DOI 10.37882/2223-2974.2020.10.12

\title{
ЦИФРОВАЯ ЭКОНОМИКА СОВРЕМЕННОЙ ФРАНЦИИ: ПОЛИТИКО-ПРАВОВОЙ АСПЕКТ
}

\section{DIGITAL ECONOMY OF MODERN FRANCE: POLITICAL AND LEGAL ASPECT}

\section{A. Kozlov}

Summary: This article analyzes in detail the policy of President Emmanuel Macron in the field of information technologies, which serve as the basis for the development of French digital economy. The author considers the measures taken for large-scale implementation of digital technologies in three different aspects - research and educational, political and managerial, and communicative. The author of the article considers four main initiatives of the French Government aimed at the development of artificial intelligence technology: the pan-European initiative FET Flagships, designed to consolidate the efforts of researchers and scientists in the field of artificial intelligence; the national Future Investment Program, which increases the attractiveness of innovative developments for young professionals; investments of the State Bank in promising French startups working in the field of information technology; Strategic Committee on Artificial Intelligence, which is engaged in systematization of proposed initiatives in the field of $\mathrm{Al}$, as well as the development of new initiatives in this direction The author pays special attention to the detailed presentation and comment on the main provisions of the Fifth Republic's national strategy called «France-Artificial intelligence», designed to accelerate the development of Al technologies as the main tool of the digital economy and smooth out the negative consequences of a possible social crisis in the process of their implementation. The main threats of the large-scale implementation of artificial intelligence technology in the sphere of French citizens' professional activity are the leakage of personal data of company clients and the emergence of an unfavorable production environment in which the efficiency of machines is put above the needs of human workers. The measures taken by the French Government to eliminate these threats are described. The conclusion is made about the necessary structural connection of the reforms with the needs of representatives of the three main levels, that constitute the national economy - state, corporate and individual. The main directions of activities, carried out by the state authorities and company owners for the introduction of artificial intelligence technology in digitalized industrial relations are defined.

Keywords: digital economy, artificial intelligence, political and managerial aspect, post-industrial world, progressive technologies, national economy, legislative activity, environmental situation, employees, personal data.

\author{
Козлов Антон Гордеевич \\ Преподаватель, ФГБОУВО «Государственный \\ университет управления», г. Москва \\ antonkozlov3000@yandex.ru
}

Аннотация: В данной статье подробно анализируется политика Президента Эммануэля Макрона в сфере информационных технологий, служащих базисом для развития цифровой экономики Франции. Авторы рассматривают принимаемые меры по широкомасштабному внедрению цифровых технологий в трех различных аспектах - исследовательско-образовательном, политико-управленческом и коммуникативном. Автором статьи рассмотрены четыре основные инициативы Правительства Франции, направленные на развитие технологии искусственного интеллекта: общеевропейская инициатива FET Flagships, призванная консолидировать усилия исследователей и ученых в сфере искусственного интеллекта; национальная Программа будущих инвестиций, увеличивающая привлекательность инновационных разработок для молодых специалистов; инвестиции Государственного банка в перспективные французские стартапы, работающие в сфере информационных технологий; Стратегический комитет по искусственному интеллекту, занимающийся систематизацией предложенных инициатив в сфере ИИ, а также разработкой новых инициатив в данном направлении. Особое внимание автор статьи уделяет детальному изложению и комментированию основных положений национальной стратегии Пятой республики «Франция-Искусственный интеллект», призванной ускорить развитие ИИ технологий как главного инструмента цифровой экономики и сгладить негативные последствия возможного социального кризиса в процессе их внедрения. В качестве основных угроз широкомасштабного внедрения технологии искусственного интеллекта в сферу профессиональной деятельности французских граждан выделены утечка персональных данных клиентов компаний и возникновение неблагоприятной производственной среды, в которой эффективность работы машин ставится выше нужд и потребностей работников-людей. Описаны меры, принимаемые Правительством Франции для устранения этих угроз. Сделан вывод о необходимой структурной связи реформ с потребностями представителей трех основных уровней национальной экономики - государственного, корпоративного и индивидуального. Определены основные направления деятельности органов государственной власти и владельцев компаний по внедрению технологии искусственного интеллекта в производственные отношения в условиях цифровой экономики.

Ключевые слова: цифровая экономика, искусственный интеллект, политикоуправленческий аспект, постиндустриальный мир, прогрессивные технологии, национальная экономика, законодательная деятельность, экологическая обстановка, наемные работники, персональные данные.

ционно-коммуникационных (ИКТ) систем. По мнению современных исследователей феномена цифрового развития государства и общества, в качестве наиболее универсальных ИКТ систем следует рассматривать интернет-платформы, служащие базой для создания и 
развития широкомасштабных государственных и общественных цифровых проектов, а также мобильные беспроводные сенсорные сети, повсеместное распространение которых позволило осуществить прорыв в сфере электронной коммерции и сделало возможным быструю бесперебойную коммуникацию между субъектами национальных экономик и транснациональной торговли.[3]

Одним из лидеров волны «европейской цифровизации» является Франция, где вклад сектора ИКТ в объем ВВП составляет около 3,8 \% (78 млрд. евро), при этом 3,6\% от данного показателя приходится на сферу предоставления информационно-коммуникационных услуг. Вышеуказанные данные позволяют говорить о стратегическом значении развития цифровой экономики для сохранения Францией ведущей политико-экономической роли на международной арене. Во второй половине 2018 г. Президент Эммануэль Макрон сделал вывод о необходимости разработки национальной стратегии по внедрению современных практических достижений в области исследования искусственного интеллекта (ИИ) в ключевые сферы французской государственной и общественной жизни.

Первым из предложенных направлений развития стало широкое реформирование принципов и сфер прикладного применения систем обмена данными, функционирующих на базе серверных кластеров Пятой Республики. Комплекс данных реформ получил название «наступательной» политики в области данных (une politique de données offensive). [4] Эксперты в области информационных технологий, призванные воплотить в жизнь политические установки Кабинета министров Франции, выделяют три наиболее перспективных направления работы по данному вопросу: исследовательско-образовательное, политико-управленческое и коммуникативное.

Исследовательско-образовательный аспект реформы позволит профессионалам в разных областях знания быстрее и проще находить в национальной сети Интернет релевантную информацию по интересующим их вопросам. Имплементация данного аспекта обеспечит повышение эффективности принятия глобальных политических решений, так как национальным политическим советникам будет предоставлен более широкий доступ к информационным источникам уже на начальном этапе разработки таких ключевых документов как, например, проект поправок к Национальной стратегии устойчивого развития, принятой Францией в 2003 г. по итогам международных переговоров на саммите $\mathrm{OOH}$ в Йоханнесбурге, или очередной пересмотр Стратегии обороны и национальной безопасности Франции в рамках реализации национального Закона о военном развитии до 2025 г. На уровне отдельных компаний данный аспект реформирования систем обмена данными позволит проводить более подробные и масштабные исследования рынка в целях повышения конкурентоспособности ключевых предприятий национальной экономики внутри страны и в процессе международной торговли, а также повысить привлекательность предпринимательского пространства Франции для учредителей филиалов транснациональных корпораций и иностранных инвесторов. Кроме всего вышеперечисленного, исследовательско-образовательный аспект, как следует из его названия, способствует развитию системы национального образования посредством повышения доступности и степени разработанности источниковой базы научных исследований, проводимых французскими учеными.

Политико-управленческий аспект посвящен реформированию процессов обработки и практического использования информации, полученной из заслуживающих доверия источников. Следует особо отметить, что практические результаты реализации данного аспекта выражаются главным образом в расширении так называемого «пространства для маневра» политиков, руководителей компаний и ученых при принятии ими решений тактического характера (в отличие от глобальных стратегических проектов, являющихся итогами имплементации исследовательско-образовательного аспекта). Таким образом, политические деятели Франции приобретают способность более оперативно реагировать на запросы населения и вызовы времени путем осуществления конкретных, точечных действий в отдельных сферах экономической и политико-правовой жизни страны (подобные действия оформляются, как правило, путем разработки и принятия специализированных законодательных актов). Предприниматели, в свою очередь, способны отслеживать ряд важнейших для них экономических показателей отдельных рынков фактически «в реальном времени», что позволяет им гибко реагировать на естественные (цикличный характер кризисов капиталистической экономики) и искусственные (совокупность конкурентных действий в предпринимательстве) изменения экономического ландшафта. [9] Французские ученые и исследователи получают возможность держать руку «на пульсе» современных наук, получая своеобразный статус «сил быстрого реагирования» при решении наиболее насущных задач постиндустриального общества (в настоящий момент, например, одной из самых срочных задач, стоящих перед современным человечеством, является разработка вакцины от коронавируса).

Коммуникативный аспект достаточно прост для понимания, однако его реализация требует налаживания отношений сотрудничества и взаимопомощи между отдельными субъектами экономической, политикоправовой и общественной жизни Франции как одного из наиболее влиятельных членов мирового сообще- 
ства. Принятие эффективных решений в совокупности с пристальным контролем за их соблюдением невозможно без объединения усилий и средств вышеуказанных субъектов. Так, например, принятие Законопроекта об уменьшении выброса парниковых газов в атмосферу, внесенный на рассмотрение Сената Франции 30 января 2020 г., потребует объединения всех разнородных политических сил страны на фоне нарастающего политического кризиса и растущего недоверия Президенту Эммануэлю Макрону. Будущий закон позволит Франции исполнить свои обязательства по улучшению экологической обстановки в Европе перед таким наднациональным экономическим образованием, как Европейский Союз. Предприниматели Франции будут обязаны придерживаться норм выброса парниковых газов при производстве товаров. Задачей ученых и исследователей в данной ситуации будет скорейшая разработка мощных экологических фильтров для промышленного использования и выпуск их в свободный оборот на национальном и международном рынках. Из всего вышесказанного следует, что цифровизация экономических, политико-правовых и общественных сфер деятельности людей позволяет преобразовать разнородные субъекты многополярного постиндустриального мира в единую функциональную многоуровневую многопрофильную систему, способную оперативно решать задачи любой степени сложности. [8]

Вторым важным направлением развития французской экономики в эпоху цифровизации является расширение области и объемов применения искусственного интеллекта (ИИ) в сфере производственных отношений. Комплексный характер задач, поставленный перед предпринимателями постиндустриального общества, предопределил факт использования ИИ в промышленности в качестве необходимого условия конкурентоспособности современного предприятия. ИИ, как сложная система симуляции рациональных элементов человеческого интеллекта, способен находить наиболее ресурсоемкие способы решения поставленных перед ним задач, а также обучаться в процессе осуществления специализированной деятельности. Таким образом, логически можно легко установить, что во многих сферах производства, не требующих творческого участия человеческой личности (большая часть заводских производств), работники физического труда могут быть заменены системами ИИ без ущерба для экономических показателей предприятий. [1]

Понимание того факта, что приобретение Францией статуса подлинно «цифровой державы» в условиях постиндустриального общества невозможно без становления искусственного интеллекта в качестве основного инструмента национальной экономики, побудило правительство Эммануэля Макрона принять ряд инициатив, направленных на закрепление позиций Пятой Республики в данной области. Первой подобной инициативой стала разработка совместной с Европейским Союзом (ежегодно предоставляющим Франции на нужды развития искусственного интеллекта 1 млрд евро) финансовой стратегии поддержки инновационных исследований в области искусственного интеллекта FET Flagships («Флагманы будущих и прогрессивных технологий»). Приоритетными направлениями исследований в рамках данной стратегии являются гибкая электроника, высокочастотная электроника и программируемые логические устройства. [6]

Второй инициативой стала программа мобилизации HR-ресурсов исследовательских институтов Франции для поиска талантливых молодых специалистов, работающих в сфере IT, привлечения их к работе над текущими проектами по развитию искусственного интеллекта путем предоставления им существенных финансовых бонусов. Данная инициатива реализуется в настоящий момент в рамках национальной Программы будущих инвестиций (Programme des Investissements d'Avenir).

Особняком стоит третья инициатива правительства Франции - план конкретных экономических мероприятий по инвестированию денежных средств в наиболее перспективные французские стартапы, осуществляющие свою деятельность в сфере искусственного интеллекта. Реализацией данного проекта занимается Государственный банк инвестиций (Bpifrance), который планирует до 2022 г. вложить сумму в 25 миллионов евро в каждый из выбранных им 25 французских ИИ-стартапов. [5]

Четвертой крупной инициативой стало создание по указу Президента Эммануэля Макрона Стратегического комитета по искусственному интеллекту, в состав которого вошли виднейшие представители академических и научных кругов, крупнейшие предприниматели Франции, извлекающие доходы из высокотехнологичных производств, а также наиболее активные представители гражданского общества. Данный комитет призван систематизировать инициативы, предлагаемые для реализации в ИИ-сфере, со стороны представителей всех наиболее компетентных и политически активных слоев населения Пятой Республики. Таким образом, для эффективной реализации всех предложенных инициатив должен быть соблюден принцип сотрудничества субъектов цифровой экономики.

По данным исследований, проведенных американской исследовательской корпорацией The McKinsey Global Institute на основании данных, полученных в результате изучения темпов развития наиболее развитых экономик Европы (в числе которых Франция стоит на первом месте) в течение ближайших тридцати лет око- 
ло половины всех существующих в настоящий момент видов производств будут полностью автоматизированы. Подобные цифры очень привлекательно выглядят при проведении теоретических расчетов и рисуют картину мира, в котором значительно ускорятся темпы производства при почти полном сокращении числа бракованных товаров посредством устранения влияния так называемого «человеческого фактора» на производственный процесс. Однако, на практике подобная «утопия» сулит катастрофические последствия для населения капиталистических стран, которое фактически лишится механизмов для реализации и отстаивания ряда ключевых прав «третьей волны», то есть социально-экономических прав, куда входят, среди прочего, право на труд и право на социальные выплаты незащищенным слоям населения (пенсионерам, инвалидам, матерям и т.д.). В целях недопущения вышеописанного развития событий французское правительство еще в 2017 г. приняло Стратегию «Франция - Искусственный интеллект» (La stratégie France І. А.), острая необходимость практической реализации которой возникла в связи с проведением движением «желтые жилеты» массовых протестов (нередко перерастающих в массовые беспорядки) на всей территории Франции. [10,2]

Первой фундаментальной задачей, поставленной правительством Эммануэля Макрона в данной Стратегии, является разъяснение вопроса об этическом аспекте использования искусственного интеллекта в сфере оказания услуг при получении, обработке и распространении личных данных клиентов. Для реализации данной задачи французские парламентарии подготовили пакет поправок к Закону о биоэтике 1994 г., широкое обсуждение которых запланировано на первую половину 2020 г. В частности, в Статью 11 данного Закона предполагается внести изменения, в соответствии с которыми медицинские учреждения будут обязаны зашифровать данные о пациентах в своих электронных базах в целях недопущения утечки информации подобного рода при ее обработке ИИ при проведении процедуры диагностики и назначения лечения. Кроме того, парламентарии обещают оперативно вносить дальнейшие изменения в вышеназванный Закон по мере развития технологий искусственного интеллекта и, как следствие, предоставления доступа к более комплексным системам ИИ коммерческим организациям в сфере производства товаров и услуг (например, внедрение новых технологий обработки баз данных клиентов заинтересованными в этом компаниями).

Вторая фундаментальная задача Стратегии логически вытекает из первой. Этическая неопределенность использования ИИ-машин при обработке персональных данных ставит вопрос о контроле за действиями ИИинфраструктуры со стороны специально подготовлен- ных работников предприятия. Таким образом, данный документ ставит перед предпринимателями, извлекающими доход из инновационных отраслей экономики, задачу «вертикального подчинения» искусственного интеллекта специалистам-контролерам из числа сотрудников-людей.

Третьей фундаментальной задачей, изложенной в Стратегии «Франция-Искусственный интеллект», является контроль французского правительства над созданием благоприятной рабочей атмосферы в коллективе, использующем ИИ-технологии, посредством преобразования традиционного рабочего пространства в инновационную «экосистему» продуктивного сотрудничества наемных работников-людей и роботов. Как отмечают современные исследователи алгоритмов функционирования искусственного интеллекта, выполнение рабочих задач людьми и машинами совместно возможно в двух исключительных случаях - 1) если машина является помощником человека при осуществлении им основных рабочих функций (концепция «La machine comme assistante»); 2) если машина является полноправным коллегой работника-человека и наравне с ним выполняет поставленные руководством задачи (концепция «La machine comme collègue de travail»). [7] Первая из вышеописанных ситуаций возможна, например, в сфере оказания медицинских услуг, где врач-специалист ставит пациенту окончательный диагноз после изучения обработанной компьютерными системами информации. Второй случай можно наглядно проиллюстрировать на примере так называемых «роботов-швейцаров», выполняющих в гостиницах и аэропортах часть работы сотрудников ресепшена.

Исходя из вышеизложенного можно сделать вывод о том, что в рамках построения экономики новой Цифровой Франции (La France Numerique) Президент Эммануэль Макрон поставил перед Правительством две следующие основные задачи: 1) осуществить процесс широкомасштабного внедрения цифровых технологий во все сферы жизнедеятельности французского общества, рассматриваемого в качестве системы, состоящей из трех взаимосвязанных уровней: политического (уровень государственного управления национальной экономикой), экономического (уровень функционирования компаний как ключевых субъектов национальной экономики), индивидуального (уровень отдельных индивидов - членов общества, вносящих свой профессиональный вклад в развитие национальной экономики); 2) обеспечить интенсивное развитие технологии искусственного интеллекта, рассматриваемого в качестве ключевого инструмента цифровой экономики, под непосредственным контролем государственных структур в целях минимизации негативных последствий цифровизации всех основных отраслей национальной экономики. 


\section{ЛИТЕРАТУРА}

1. Богуславский А.А., Боровин Г.К., Карташев В.А., Павловский В.Е., Соколов С.М. Модели и алгоритмы для интеллектуальных систем управления/М.:ИПМ им. М. В. Келдыша, 2019. 228 с.

2. Ефанова Л.Д. Движение «желтые жилеты» во Франции: проблемы, причины, перспективы/ Управление. 2019. № 2, Том 7 - С. 133-138.

3. Стародубцева Е.Б. Влияние развития цифрового сектора на национальные экономики/Россия: тенденции и перспективы развития. 2019. Вып. 14. Ч. 2. C.336-341.

4. Cédric Villani, Marc Schoenauer, Yann Bonnet, Charly Berthet, Anne-Charlotte Cornut, François Levin, Bertrand Rondepierre. Donner un sens à l'intelligence artificielle: Pour une stratégie nationale et européenne [Осмысление искусственного интеллекта: для национальной и европейской стратегии]/Мission du Parlement européen, 2018. - $235 \mathrm{p}$.

5. Jö̈l-Thomas Ravix, Marc Deschamps. Innovation and Industrial Policies [Инновации и индустриальная политика]/ Wiley-ISTE; 1 edition, 2020. - 194 p.

6. Matts Benner. The New Global Politics of Science. Knowledge, Markets and the State [Новая глобальная политика в сфере науки. Знания, рынки и государСтВ0]/Edward Elgar Publishing, 2018. - 232 p.

7. Salima Benhamou, Lionel Janin. Intelligence artificielle et travail [Искусственный интеллект и работа]/ France Stratégie, 2018 - 90 р.

8. Chiffres clés du climat France, Europe et Monde [Главные цифры по французскому, европейскому и мировому климату]/Commissariat général au développement durable, 2019. - $80 \mathrm{p}$.

9. La Stratégie internationale de la France pour le numérique [Международная стратегия для цифровой Франции]/ Le Gouvernement de la République française, 2018. $-34 \mathrm{p}$.

10. Un Livre blanc:Intelligence Artificielle - Une approche européenne axée sur l'excellence et la confiance [Белая книга: Искусственный интеллект - Европейский подход, нацеленный на высокое качество и доверие]/ La Commission européenne, 2020. - 31 p.

(с) Козлов Антон Гордеевич (antonkozlov3000@yandex.ru).

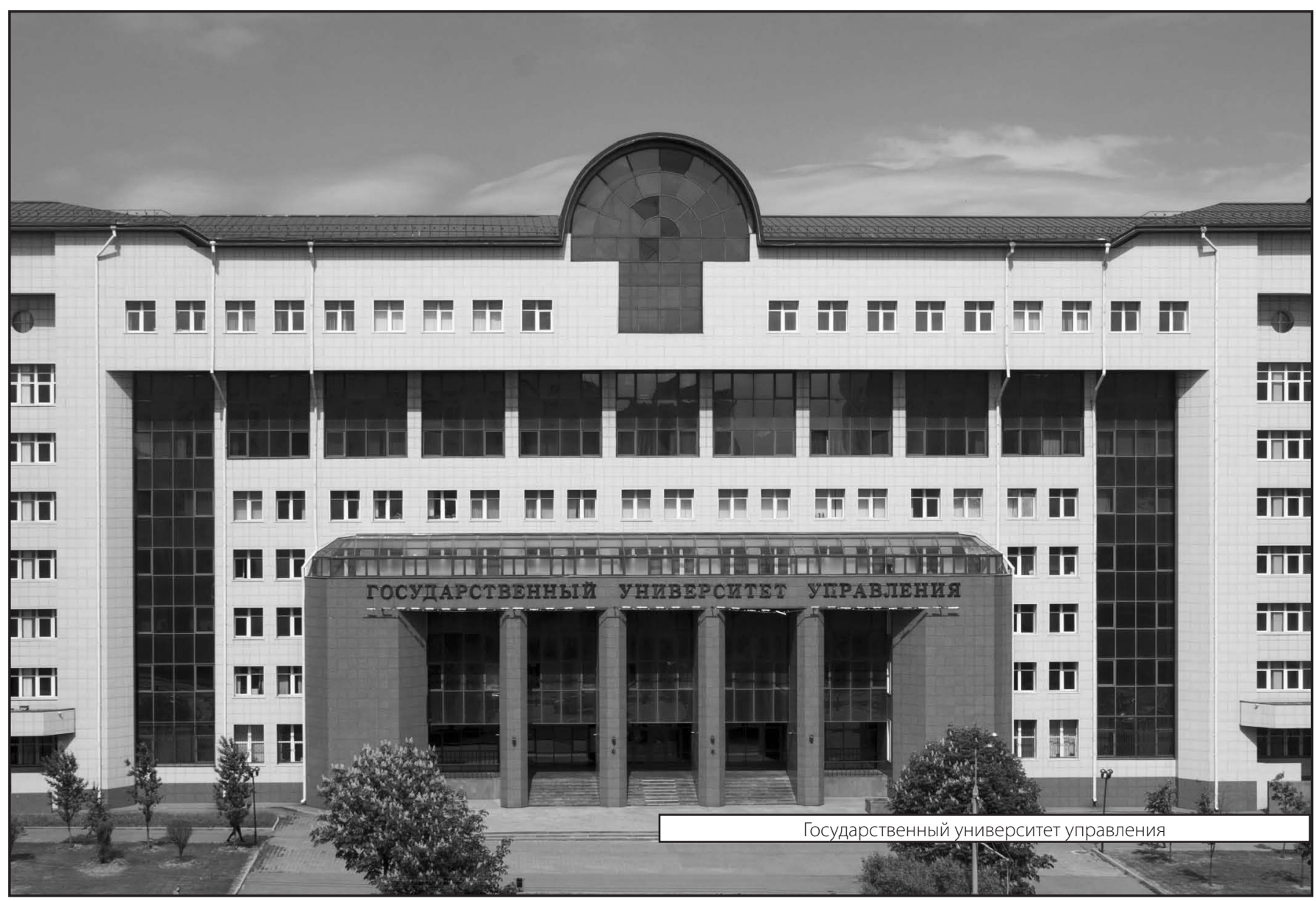

